\title{
Sonic Maps: \\ On the Acoustic (Trans)Formation of Urban Space in Straight Outta Compton (2015) and Grand Theft Auto (1997-2013)
}

\author{
Martin Butler \\ Carl von Ossietzky University of Oldenburg \\ martin.butler@uni-oldenburg.de
}

Received 18 November 2019; accepted 20 September 2020; published 21 December 2020.

\begin{abstract}
This contribution sets out to explore the sonic dimension of representing the city in the film Straight Outta Compton (2015) and the computer game series Grand Theft Auto (1997-2013). It analyzes the ways in which sounds and noises produced in and through these media contribute to constructing urban settings - not only in geographical terms, but also with regard to the various lines of (ethnical, racial, class or gender) demarcation that turn these settings into highly contested spaces characterized by power-laden processes and dynamics of social and cultural in- and exclusion. To do so, the article identifies the aesthetic means the film and the game series employ to render specific areas/sites of the city. At the same time, it explores the technological options of what is referred to as "sonic mapping" by also taking into consideration the forms and potential functions of 3D-sound in contemporary (home) cinema.
\end{abstract}

Keywords: soundtracks; sound technologies; sonic mapping; urban space; film; computer games

In many different ways, popular cultural practices and forms of expression shape the ways in which we conceptualize and experience urban space - be it through camerawork in films such as The Fast and The Furious, which introduces us to urban sceneries by means of superfast car races and chases, through gangsta rap music, which provides us with acoustic renditions of what is (supposed to be) experienced as "the ghetto", or through computer games such as Grand Theft Auto, in which the players navigate a fictitious US American metropolis to indulge in criminal activities. Popular culture significantly contributes to the formation and transformation of what Kevin Lynch, in his The Image of the City (1960), has called a "mental map" of urban environments, prefiguring our ideas about cityscapes as well as our actual experiences of navigating urban contexts. 
Taking this observation on the (trans)formative potential of popular culture as a starting point, this article sets out to explore the role of the sonic dimension in the shaping and reshaping of urban space, focusing on F. Gary Gray's biopic Straight Outta Compton and - to open up a perspective on a different audiovisual medium - also touching upon Rockstar North's computer game series Grand Theft Auto. I analyze the ways in which specific sounds produced in and through these media contribute to constructing urban settings - not only in geographical terms, but also with regard to the various lines of (ethnical, racial, class or gender) demarcation that turn these settings into highly contested spaces characterized by power-laden processes and dynamics of social and cultural in- and exclusion. Therefore, what follows sets out to reconstruct what I would like to call the "sonic maps" (re)produced in these media, identifying the aesthetic means they employ to render specific areas/sites of the city ("the suburbs", "the outskirts", etc.) through the use of music, language, and the emulation of what is usually conceived of as "city noise", i.e. sounds that the city produces (and that produce the city) "collaterally", e.g. through the movement and interaction of vehicles and people. At the same time, my contribution also explores the technological options of sonic mapping by also taking into consideration the forms and potential functions of what has been commonly referred to as 3Dsound in contemporary (home) cinema.

By discussing the two examples, I would like to push into the foreground the auditory dimension of audiovisual media, the role of which in the production of space should not be underestimated. As William Whittington reminds us, "(i)n this age of visual culture, it is important to remember that "sound is half the picture"' $(2007$, p. 1). Indeed, complementary to the visuals of films or computer games, through which images of urban space are (re)produced in a number of different ways, it is their acoustic track which adds to the formation and transformation of an experience of urban space among the viewers, constantly interacting with what we see on screen. This intermedial interplay between images and sounds produces what Michel Chion has called a "conceptual resonance": "the sound", he argues, "makes us see the image differently, and then this new image makes us hear the sound differently, which, in turn makes us see something else in the image, which makes us hear different things in the sound, and so on" (1990, p. xxii, cf. Harper, 2009, p. 3). The soundscape of films and other audiovisual media, then, consisting of both the dialogues, sounds and noises within the diegetic world of the narrative and the extradiegetic music and other acoustic tracks (including, e.g., the introductory and closing credits or a voice-over narration), significantly contributes to the aesthetic experience of watching a film or playing a computer game.

As hinted at above, this significance of sound design has grown substantially with the advancement of sound production and dissemination technologies, eventually leading to what has become known as 3D-sound effects provided by formats such as Dolby Surround, THX, or more recently - Dolby Atmos or Auro 3D. All of these - both in cinemas and in private living rooms - have enabled the production of soundscapes that are no longer limited by two stereo channels, but complement the visual dimension of representation in a much more complex way. While the visual experience is still framed by the physical limits of the TV set or monitor we look at, sounds reach us from virtually every direction through "multi-channel environments" (Kerins, 2010, p. 70). What we see and what we hear, then, is modelled into a composite experience of the fictional world, as "audiences will understand sounds originating in the surround channels to be part of the same diegetic space as those originating onscreen" (Kerins, 
2010, p. 70): we can hear car or helicopter noise or the voices of characters that can no longer (or not yet) be seen on screen, drops of rain are rendered acoustically, coming down on us through speakers in the ceiling. In other words, we are embedded by or involved in soundscapes that, through new technologies, are not only spatially dispersed, but are becoming increasingly differentiated at the same time, as "(d)igital surround sound ... offers completely discrete audio channels", which results in "the ability for literally more sounds to play at the same time" (Kerins, 2010, p. 65). This, in turn, contributes to the creation of "authentic" "lifelike atmospheres" (Dolby, qtd. in Kerins, 2010, p. 67), which are, through the separation into different channels, "more perceptible" for the audience (Kerins, 2010, p. 67, all emphases in the original).

The soundscapes produced and mediated through this technological set-up impact on the ways we receive a film and the space it represents. As Tania Gentic argues in her analysis of Fernando Pérez's 2003 film Suite Habana, "sound modifies the film's ideological and visual representations of the city by creating an aural imaginary that represents an affective and corporeally felt notion of community" (2014, p. 199). According to her,

the film changes the reception of the image by expanding the viewing subject into a listening subject as well. This subject perceives sound as occurring in a spatialized, affective, and corporeal community that links the Havana on the screen to the space of the theater or home in which the audio-viewer perceives the city. (Gentic, 2014, p. 199)

"To put it another way", she concludes, "our subjective experience of space derives from our exposure to representations - and re-presentations - of it, breaking down the distinction between a simulated image and a 'real' one" (Gentic, 2014, p. 200).

This "aural imaginary", then, through which urban space is re-presented, affects the viewer/the listener by embedding him/her in a virtual world of sounds and noises. Watching/listening to a film thus becomes a physical experience that also contributes to shaping the collective experience of the audience. For Gentic, "the aural imaginary always implies the body of the spectator in space, not just the body represented on the screen, and it produces an emotional tie between them" (2014, p. 201). This way, "it creates a form of community through the auditory structure of listening that expands the experience of Havana into a soundscape that exceeds that of the screen" (Gentic, 2014, p. 202). Consequently, "the geographical barriers that would otherwise separate not only one neighborhood from another, but also the audio-viewer from the subjects portrayed in the film, are erased as sound 'escapes' into a space that goes beyond the screen" (Gentic, 2014, p. 215).

Yet, the production of space through the acoustic track of films or computer games is not only characterized by this disseminating, "escaping" quality of sound and noise, but also by what I would like to call "sonic reconfiguration", i.e. the referencing of earlier acoustic representations of urban settings (such as Hollywood, the Bronx, Compton) in order to, e.g., enhance their recognizability or to mark the film or game as belonging to a specific genre. Thus, in addition to taking into account the interplay between sounds and the visual dimension of audiovisual media, one also needs to consider the interplay of a film's or game's soundscape with other acoustic renderings of urban space (e.g. in music, in other films). In other words, and with reference to the concept of mimetic representation as outlined by Paul Ricoeur (cf. 
1984, esp. pp. 52-88), “aural imaginaries", i.e. ideas of a specific place as articulated in and through audiovisual media, are always medially "prefigured" by preceding representations; in an act of "configuration", then, these media reassemble sounds and noises in a specific way in order to produce a specific version of the urban settings they represent. These newly configured "sonic maps", in turn, bear the potential to "refigure" our ideas of what constitutes a specific urban environment.

One example, in which both the technological parameters as well as the references to other forms of sonic representations are at work in order to produce such an imagined urban environment, is the 2015 film Straight Outta Compton, directed by F. Gary Gray. Rendering the rise and early career of the hip hop group NWA, this film can clearly be identified as a somewhat "late addition" of what has commonly been referred to as the "hood genre" (Haupt, 2017, p. 208, referring to Wiggins), which "dominated early to mid-1990s black cinema" (Bradley, 2017, p. 143). Constituting "[a] subgenre of urban black films spearheaded by directors like John Singleton, Albert and Allen Hughes, Mario Van Peebles, and F. Gary Gray", as Regina N. Bradley explains,

hood films pivoted on the gritty reality of how working-class blacks, with particular attention to young working-class black men, struggled (often for naught) for better lives and to simply live. Films like Boyz 'n the Hood (dir. John Singleton, 1991), New Jack City (dir. Mario Van Peebles, 1991), Juice (dir. Ernest R. Dickerson, 1992), and Menace II Society (dir. Albert Hughes and Allen Hughes, 1993) offered Hobbesian renderings of inner-city black life as short, poor, nihilistic, and unforgiving. (2017, p. 143)

And, as Bradley continues, "hood films often showcased the rap talent in front of the screen and as contributors to film soundtracks. For example, Ice Cube, who proved to be just as vicious a performer onscreen as he was an emcee, was heavily utilized by Singleton in many of his films to star as the quintessential hood thinker" (2017, p. 143).

Straight Outta Compton evokes the era of the rise of hip hop (i.e. the 1980s and 1990s) not only through its focusing on NWA's early career, but also through its title, which is eponymous with the group's first album released in 1988. In so doing, it "draws on the same conventions that the hood movie genre as well as gangsta rap employ" (Haupt, 2017, p. 208). As part of these conventions, the film uses a soundtrack that includes a set of sounds and noises particularly apt to render its urban setting - Compton - as a neighborhood mostly inhabited by poor African-Americans, which is further characterized by high degrees of juvenile delinquency and deviance. In this vein, then, Adam Haupt describes the film's opening sequence as follows:

Straight establishes this hostile context in which its protagonists attempt to exercise agency, much on line with films such as Boyz $N$ the Hood. The film opens with audio samples of a police radio dispatcher and news media coverage of the hood. As an animated sequence of the Universal and Legendary company logos plays, we hear a police radio dispatcher discussing a location, a dog barking, a helicopter flying overhead, and media snippets (2017, p. 209)

which all indicate that we are set in an urban context characterized by crime, drugs, and violence. Haupt then illustrates how the first two songs featured in the film, Dr. Dre's "Straight 
Outta Compton" and his "Talking to My Diary" add to establishing the atmosphere of the film, re-producing an aural imaginary of Compton prefigured by the generic conventions of the hood film. Within this aural imaginary, it is the adolescent African-American male who, through voicing the hardships of life on the streets, takes center stage, and whose racialized deviance is indicated through the noises of surveillance (the dog, the helicopter, the media). These noises, it seems, constantly endanger the precarious and highly fragile intimacy of home as the last resort. Accordingly, the movie's protagonist is produced as a social outcast through a range of sonic cues even before we are confronted with the urban scenery on the visual level.

The production of this subject position is enhanced through recording and screening technologies: the film's soundtrack, recorded in the DTS:X audio format, which, as a variation of 3D sound, allows the sound to be disseminated not only from the surround speakers of a (home) cinema, but also from speakers mounted to the ceiling, enhance the aural experience of a complete immersion into the space represented through the acoustic track. And indeed, in the sequence that Haupt describes, the audience is not only confronted with, but literally "embedded" by the "police radio dispatcher", "media snippets", and the "helicopter flying overhead", the noise of which is partly disseminated by adequately placed ceiling speakers. Thus - very much in analogy to the production of the film's protagonist - we are exposed to Compton's sonic environment before we see what it looks like on screen.

But how do we know that we are listening to the sounds of Compton in the first place? How do we associate the sounds with a specific part of the city of Los Angeles? We do so, I argue, because our "sonic map" of Compton has already been established through our knowledge on (the clichés of) gangsta rap, predominantly mediated both on the lyrical level as well as through the regular sampling of police and crime scene noises in this genre. In other words: our hearing has been sonically prefigured through a previous media images of this specific urban space and its subjects: in conjunction with our genre expectations, then, which contribute to setting the stage for the soundscape we are about to encounter, we are thus prepared and enabled to imagine a neighborhood without any visual impression at hand, with the given sonic cues rendering the environment perhaps more instantly and comprehensively than the sequencing of visual impressions would allow. Acoustically, then, the production of Compton is very much in line with earlier medial representations of the area and ties into the almost mythical narrative of the birth of gangsta rap in the poverty-stricken areas of Los Angeles. In this way, the 2015 film adds to the almost iconic status of Compton as the paradigmatic example of African-American working class poverty, an image that had been the result of what Josh Sides has called a "dreary metamorphosis from place name to metonym" (2004, p. 596) mainly in the second half of the twentieth century, with Compton being increasingly associated with a place of delinquency and deviance in the public imagination. "By 1973, for example, the Los Angeles Times unceremoniously described Compton as a 'ghetto of poverty, crime, gang violence, unemployment and blight"” (Sides, 2004, p. 596).

Interestingly, Sides also identifies popular culture to be partly (if not significantly) responsible for this metamorphosis, as he continues: 
If this transition [of Compton's image, M.B.] had begun prior to the 1980s, it was greatly accelerated by the release of Straight Outta Compton (1988, Ruthless/Priority), by the rap group NWA ("Niggas With Attitude"). Banned from most radio stations - and more important, MTV - the album nonetheless became an instant hit, ultimately selling more than three million copies [...] Setting aside the album's historic role in the long-standing debate over freedom of artistic expression in the United States, much of the significance of Straight Outta Compton lay in its definitional power, its role in creating a national, even global, perception of a place largely disconnected from its history. (2004, pp. 596-597)

Indeed, hip-hop culture provided the "soundtrack of the hood", and, what is more important, produced a specific "sonic map" of Compton that should become and remain highly influential up until today: "After NWA, 'Compton' became a virtually irresistible, and imminently exploitable, metonym for rappers, and more influentially, filmmakers" (Sides, 2004, p. 598). The medially formed idea of Compton, as one may argue, thus prefigured the so-called "hood"film of the 1980s and 1990s, and eventually, also impacted on Gray's 2015 biopic on the career of NWA, in which hip hop music is omnipresent: "You have the NWA music and its edginess and what NWA is", as Billy Fox, the film's editor, points out (qtd. in Hullfish, 2017, p. 187). "Then you have a tremendous amount of 'source': the stuff that's coming out of the radio and the stuff being played in the background and that sets the tone and sets the time and place" (qtd. in Hullfish, 2017, p. 187).

That the "soundtrack of the hood" is not only significant for the audience to identify the film's urban setting, but also for the diegetic world of the film's protagonists in terms of their identity performance, is already indicated in the film's first scene (00:00:49-00:01:02). Here, we witness the character of Eazy-E drawing a huge loudspeaker out of a cabinet in the trunk of his car, in which he hid a gun. The close-up shot of the loudspeaker cabinet and the gun, as one may well argue, again emphasizes the close connection between rap music and an ethics of deviance, and, as Haupt argues, it is through this scene that "we already know that Eazy E is about to step into a dangerous situation" (2017, p. 209). Moreover, in the course of the film, rap songs by NWA are featured as live performances, which visually underlines the significance of their music as identity politics, as their voice is 'embodied' through their physical appearance on stage. At the same time, their concerts are featured as spaces in which the band's specific aesthetic and ideological position is regularly shown to be supervised, and thus contained, by the body, or bodies, of the police. ${ }^{1}$

Apart from clearly demarcating themselves from the institutions that represent hegemonic whiteness, NWA distinguishes themselves from yet another notorious "opponent" of what is shown to emerge as West coast gangsta rap: i.e., the New York hip hop scene, which, by the end of the 1980s, had already made significant steps in the development of a distinct subcultural scene. This artistic antagonism between the two coasts is also rendered through sound, when the members of NWA are shown listening to an New York rap group in their studio,

\footnotetext{
${ }^{1}$ Haupt's illuminating analysis of Straight Outta Compton, which I am drawing on here and elsewere in my contribution, elaborates in detail on this opposition and examines the film's use of rap music's potential as a critical intervention in racist discourses. Moreover, he also embeds Straight Outta Compton in the context of other 'hood films' and their use of rap music, connecting it to contemporary political debates about racism in the United States, while hinting at its lack of sensitivity towards the category of gender.
} 
having difficulties to grasp their lyrics, as they draw upon a regionally specific "urban dictionary" as well as accent (00:24:59-00:25:20):

- What the fuck is "gankin"? And what's a "6-4"?

- Yeah.

- It's a car. A 6-4 Impala.

- "Ganking" is when you jack somebody, man. (00:25:04-00:25:13)

Compton, which, for the New York group, does not exist on the "map" of US American hip hop culture at the time ("I mean, besides, who gives a fuck about Compton anyway?", 00:25:19-00:25:20) is thus produced through a specific lexicon and articulation, through a slang that links a specific urban setting to a particular variation of hip-hop and, accordingly, to a distinguishable artistic and ideological position.

Another function of this "soundtrack of the hood" is to demarcate public from private places: usually, the white noise of the streets, the hip hop beats of gangs meeting at night, and the sirens of police cars are muted, or excluded, when the characters enter their homes or the homes of friends, signaling a more intimate atmosphere of privacy. So, there are indeed ways out of the "hood", which lead into more caring, more sensitive and more emotional environments, rendered through low volumes of speech and music. For instance, when Eazy-E, in one of the establishing sequences of the film, comes back home to his girlfriend after escaping a police raid, an atmosphere of privacy and intimacy is established as his closing the door prevents the sounds and noises of "the hood" to invade their living room.

And, as the film reminds us, these sounds and noises can be utterly overwhelming: in its rendering of the so-called "LA riots" (01:46:15-01:47:23), i.e. the culmination of the conflict between African-American citizens and the Los Angeles police after a series of racist police violence in the area in the spring of 1992, the film indeed uses a highly dense soundscape to emphasize the tenseness of the situation. It confronts the audience with multiple layers of street noises, police sirens, a helicopter's rotor and media footage, which, through their complex overlay, add to the overall confusion of the situation. Again, sounds and noises are disseminated three-dimensionally through the DTS:X-format, absorbing the audience into the riotsscene, thus turning them into participants rather than mere observers. Suddenly, then (at 01:47:24-01:47:30), as if to indicate a complete breakdown (of the transmission of images and sounds as well as of the people involved), the screen turns black, and what remains is the sound of a shrill ringing in the ears (both of the characters on screen and of the film's audience), indicating that the sound pollution of the neighborhood due to the dramatic events has indeed become unbearable, literally unhealthy. During the sequence portraying the riots, voiceover samples from media reports on the events underline the highly destructive, battle-like scenario, pointing out that "it looks kind of like we're in a war zone though" (01:46:3101:46:32) characterized by "anarchy" (01:46:37) and the police's use of "military-style assault weapons" (01:46:48).

In sum, Straight Outta Compton draws upon a number of sonic cues to establish its major setting. The combination of rap music, whose lyrics deal with the deviant and subversive life on the streets of the L.A. neighborhood ("Fuck the Police"), a specific African American accent plus a slang lexicon, as well as noises that indicate the "problematic" character of the 
hood and the necessity of constant observation and control (such as police sirens or helicopter noise) contribute to the production of a sonic cartography of Compton which, at the same time, maps (and thus reproduces) a socio-ethnically segregated community. In this process, which Karin Bijsterveld has called "acoustic profiling" (2013, p. 18), the film both draws upon and reproduces a number of "sonic icons" (2013, p. 15) of gangsta rap and the "hood movie", which - through 3D sound dissemination - immerse the audience into the experience of a specific urban environment constituted by social, ethnic and cultural demarcation lines, drawn both on the visual and the acoustic level of filmic representation.

To be sure, apart from the "hood movie genre", African-American slang and hip-hop culture as acoustic markers of particular neighborhoods are also used in other film genres. More often than not, they function as ciphers used to render (mostly stereotypical) maps of places that have already been firmly established in the public imagination. For instance, long before processes of gentrification would begin to turn Harlem into one of the more expensive areas to live in at the end of the 1990s, the second sequel of the Die Hard film series featured a sonic map of Harlem that was specifically characterized by the sounds of hip-hop culture. When John McLaine, the protagonist of Die Hard with a Vengeance (1995) is blackmailed at one point in the film, being forced to walk around Harlem naked, only covered by a painted sign saying "I hate niggers", he is confronted by a group of African American adolescents who obviously do not appreciate this statement, to say the least. They spot him while listening to rap music from their boom box on the street, a situation reminiscent of the early hip hop 'bloc parties' taking place particularly in uptown New York City in the late 1970s and 1980s. Much like in Straight Outta Compton, the acoustic mise en scène working in the background of this sequence thus contributes to indicating the ethnic, social and cultural topography of the environment. By taking up the acoustic inventory of hip hop culture, it evokes an African-American cultural tradition and practice that is generally held to be rooted in this part of the City, thereby (re)producing a specific image of Harlem as a socially, racially and culturally demarcated space through sound.

This form of acoustic cueing in film, employed to produce a sonic map of the region they are set in, can also be found in computer games. Similarly to film, they use sound to establish their spatial dimension, which, as Espen Aarseth and Stephan Günzel point out, "due to the dynamic nature of simulations, was acknowledged as a constitutive factor of game designing and playing games; their sine qua non" (2019, p. 7). The highly successful computer game series Grand Theft Auto is perhaps one of the most prominent examples in this respect. Basically, it involves players in stories that usually revolve around a range of criminal and often explicitly violent activities that lead up to or are the result of one another. Indeed, Grand Theft Auto's major narratives build on "classic slasher films, mob sagas, car chases, and a rich legacy of action adventures" (Murray, 2005, p. 91). While some reviewers have criticized the series for its celebration of violence and crime (cf. e.g. Murray, 2005, p. 91), others have read it as a serious (if exaggerated) "social commentary" (Murray, 2005, p. 91), and have not become tired of stressing the unique gaming experience it provides.

Apart from employing the usual street sounds and noises, a central component enabling this experience is the game's use of music. Indeed, Grand Theft Auto has been praised for its "musical soundtrack system as an innovative design feature that improves gameplay immersion" 
(Miller, 2007, p. 402, referencing Spence). While being on their deviant missions in the "open world" of Grand Theft Auto, players can choose to listen to different radio programs aired by various stations, which "are ... present in places where the game's character might plausibly find them: in the gameworld's retail establishments, in the homes and cars of the avatar's allies, and in the cars that the player steals" (Miller, 2007, p. 402). Accordingly, the exposure to radio sound varies, as other sounds and noises come into play to provide a full immersion experience. For instance, when players decide to explore the game's world by car, they "can also choose the music to accompany their exploits" (Miller, 2007, p. 402). As soon as they opt to move "(o)n foot, the city soundscape consists only of traffic noise, the comments of passersby, and occasionally the radio stations selected by non-playable characters" (Miller, 2007, p. 403). In this vein, the franchise combines "keynote sounds" (Bijsterveld, 2013, p. 15), i.e. "sounds that make up the background sound of a sonic environment" (Bijsterveld, 2013, p. 15), with more foregrounded acoustic elements that signify specific locations.

As Kiri Miller concludes, "( $\mathrm{t}$ )he player-controlled radio stations not only increase the verisimilitude and immersive qualities of each gameworld, but also encourage players to associate particular music with particular characters and places" (2007, p. 404, cf. also Annandale, 2006). Whereas in some games of the franchise, this association is not very strong (cf. Miller, 2007, pp. 411-412), it is all the more significant in others. In Grand Theft Auto: Vice City (2002), for instance,

Vice City is Miami 1986, and its music is place- and time-specific from the very beginning. The man who picks up Tommy Vercetti (the protagonist, MB) at the Vice City airport is listening to a salsa station. The first time Tommy drives a car the radio is playing Michael Jackson's "Billie Jean". ... A Spanish-language station, Radio Espantoso, represents a major step in linking the radio to the game's locale. (Miller, 2007, p. 412)

Grand Theft Auto: San Andreas (2004), in contrast, features "ghetto life" in a number of urban environments that are strikingly reminiscent of some of the best known, almost iconic places of African American subculture, among them an area called "Ganton" (obviously a rendition of L.A.'s Compton). In doing so, as Murray observes, the game “emulate(s) 1990s genre 'hood films like Colors (1988), Boyz N the Hood (1991), and Menace II Society (1993)" (2005, p. 92). In the virtual modelling of San Andreas, too, sounds and noises play a significant role in the proliferation of a sonic map (cf. Murray, 2005, p. 92). And, again, it is the radio stations that contribute significantly to the establishment of a particular urban setting, with the heavily rotating tracks functioning as coordinates that indicate both a specific region and a specific historical era:

In San Andreas, as in the earlier permutations of the game, hit records from the appropriate time period situate the player into a proper chronology. The gangsta rap from the early nineties that blares from the cars CJ [the protagonist, MB] drives includes NWA, Dr. Dre, Eazy E, and Tupac, all of whom voice the problems of police brutality, the inability to find legitimate work, and the harshness of ghetto life. (Murray, 2005, p. 95)

Yet, the sounds of the city do not only remind the players of a specific period in the history of hip hop, but also contribute to mapping the virtual world through its referencing the aesthetics and ethics of "ghetto street life" through music, evoking the "forbidden narrative" (Rose, 1994) of deviance and resistance frequently associated with and reproduced by hip hop. In so doing, 
the soundscape established through the tracks broadcast by the radio stations both reproduces a particular spatiotemporal imaginary of "the hood" and offers a frame of reference for the playing subject to relate to or identify with - a subject, which can well be assumed to be male and - if one follows Tricia Rose's findings on the affective potential of the forbidden narrative of hip hop - predominantly comes from a white middle-class background.

Moreover, the soundscape of the game also includes details of car noises in close, mid and far range. Alistair MacGregor, lead audio programmer of Rockstar North (i.e. the game's producing company), explains that these noises - including the "metallic tick of an engine cooling" as characteristic of an individual vehicle as well as the noise of "busy freeways" and of "distant cars ... driving aggressively" - were not only chosen to indicate a specific spatial position, but also to make mobility between positions audible (GDC, 2016). The noise set-ups thus change in composition and volume depending on the position of the player in the game. In this way, they contribute to the experience of spatial immersion in a specific urban setting.

The creation of what MacGregor calls an "immersive world", then, followed a set of programming "rules" through which particular attention is paid to the interaction of sounds and their contexts of articulation and dissemination (GDC, 2016). In MacGregor's words: "We consider what does the environment sound like, how are sounds affected by the environment, but also how does the environment respond to the sounds that are played back within it" (GDC, 2016). With the help of these parameters in sound design, then, the map of Grand Theft Auto's urban setting is both divided into and (co)produced by what he calls "ambience zones" - for GTA: San Andreas, he lists 949 of these zones, 1,210 "rules" according to which they have been programmed, and 518 of so-called "static emitters", which, in this case, are the radios from which music can be heard. With the help of "distance effects", "occlusion", "reflections", "reverberations", "resonances" and "shockwaves" - what MacGregor calls "Environmental Audio" - the game's audio design contributes to the production of space (GDC, 2016). Consequently, the sound design of Grand Theft Auto: San Andreas, as a combination of music and "city noise", enables users to draw on these "ambience zones" to navigate Los Santos, the game's fictional setting (GDC, 2016). Sound and noise, then, work as means of orientation to facilitate the gameplay and foster immersion. Similar to the medium of film, the option of enabling Dolby Digital 5.1 surround sound while playing the game adds to this immersive experience, as the player is exposed to the city's soundscape through multiple channels.

To conclude, the production of urban space through sound in the two examples I have focused on takes place on different levels - be it through the use of a specific musical score or through the integration of music as part of the fictional world, through a particular accent, dialect or sociolect in spoken language, or through the use of place-specific sounds and noises created by the environment. Yet, apart from the kind of sound or noise that can be heard, it is their particular quality defined by the parameters of their production and dissemination that contributes to the experience of space. It is through these different types and ways of aural representation that the viewer (of the film) or player (of the game series) can experience immersion in the story represented, which invades and embraces their physical space of reception through the distribution of aural information. In this sense, then, technology, e.g. through a speaker setup which reproduces three-dimensional sound, contributes to the immersion into the world of the film or the game. In producing aural imaginaries, the film and the game both reproduce 
soundscapes by drawing on an existing sonic repertoire to represent urban settings, making it easier for an audience/for users to identify a certain place and its specific social, economic, linguistic and cultural features. In other words, we are able to categorize the sounds and noises we encounter when watching the film or playing the computer game by comparing them to sounds and noises we already know from other medial representations of urban contexts. So, in as much as films and computer games like the ones focused on in my contribution provide us with acoustic cues that help us make sense of their setting, the creation of a meaningful world through acoustic immersion always also depends on the individual viewer's or user's (often medially) prefigured ideas of what a specific place sounds like. Accordingly, sound is indeed 'half the picture', as it both participates and lets us participate in the 'narration' of urban environments, thus significantly shaping our imagination about their central characters and characteristics.

\section{References}

Aarseth, E., \& Günzel, S. (2019). Introduction: Space - the theoretical frontier. In E. Aarseth \& S. Günzel (Eds.), Ludotopia: Spaces, places and territories in computer games (pp. 7-9). Bielefeld: transcript.

Annandale, D. (2006). The subversive carnival of Grand Theft Auto: San Andreas. In N. Garrelts (Ed.), The meaning and culture of Grand Theft Auto: Critical essays (pp. 88-103). Jefferson: MacFarland.

Bijsterveld, K. (2013). Introduction. In K. Bijsterveld (Ed.), Soundscapes of the urban past: Staged sound as mediated cultural heritage (pp. 11-28). Bielefeld: transcript.

Bradley, R. N. (2017). Introduction: Hip-hop cinema as a lens of contemporary black realities. Black Camera, 8(2), 141-45.

Chion, Michael (1990). Audio-vision: Sound on screen. (C. Gorbman, Ed. \& trans.). New York: Columbia University Press.

GDC. (2016, May 18). The sound of Grand Theft Auto V. [Video]. YouTube. <https://www.youtube.com/watch?v=L4GuM15QOFE>

Gentic, T. (2014). Beyond the visual city: The sound of space in Fernando Pérez's "Suite Habana". Hispanic Review, 82(2), 199-220.

Grand Theft Auto: San Andreas [computer software]. (2004). New York: Rockstar North/Rockstar Games.

Grand Theft Auto: Vice City [computer software]. (2002). New York: Rockstar North/Rockstar Games.

Gray, F.G. (Director). (2015). Straight Outta Compton [Film]. Legendary Pictures/Universal.

Harper, G. (2009). Introduction: Sound in film and visual media. In G. Harper, R. Doughty \& J. Eisentraut (Eds.), Sound and music in film and visual media: A critical overview (pp. 1-14). London: Bloomsbury. 
Haupt, A. (2017). "True to the game": Straight Outta Compton's affirmation of white supremacist capitalist patriarchy. Black Camera, 8(2), 208-25.

Hullfish, S. (2017). Art of the cut: Conversations with film and TV editors ( $1^{\text {st }}$ ed.). New York, London: Routledge.

Kerins, M. (2010). Beyond (Dolby) stereo: Cinema in the digital sound age. Bloomington: Indiana University Press.

Lynch, K. (1960). The image of the city. Cambridge, London: MIT Press.

McTiernan, J. (Director). (1995). Die hard with a vengeance [Film]. Cinergi Pictures; 20 ${ }^{\text {th }}$ Century Fox.

Miller, K. (2007). Jacking the dial: Radio, race, and place in "Grand Theft Auto". Ethnomusicology, 51(3), 402-38.

Murray, S. (2005). High art/Low life: The art of playing "Grand Theft Auto". PAJ: A Journal of Performance and Art, 27(2), 91-8.

Ricoeur, P. (1984). Time and narrative, volume 1. (K. McLaughlin \& D. Pellauer, Trans.). Chicago: University of Chicago Press.

Rose, T. (1994). Black noise: Rap music and black culture in contemporary America. Hanover: Wesleyan University Press.

Sides, J. (2004). Straight into Compton: American dreams, urban nightmares, and the metamorphosis of a black suburb. American Quarterly, 56(3), 583-605.

Whittington, W. (2007). Sound design and science fiction. Austin: University of Texas Press.

Martin Butler is Professor of American Literary and Cultural Studies at the University of Oldenburg, Germany. His research interests include popular music, forms and figures of cultural mobility, and cultures of participation in new media environments. Apart from a broad range of articles in these fields, he published a monograph on Woody Guthrie (Voices of the Down and Out, 2007) and co-edited nine essay collections, including Sound Fabrics: Studies on the Intermedial and Institutional Dimensions of Popular Music (2009, with Patrick Burger and Arvi Sepp), a special issue of Popular Music and Society on musical autobiographies (2015, with Daniel Stein) as well as a volume on Resistance: Subjects, Representations and Contexts (2017, with Paul Mecheril and Lea Brenningmeyer).

The editorial and publishing process of this publication has been financed by the Ministry of Science and Higher Education from the funds for the dissemination of research (DUN) within the framework of publishing activity, contract no. 711/P-DUN/2019, period of implementation: the years 2019-2020. 